\title{
Optimal decisions based on monitoring - case study of steel roof
}

\author{
Daniele Lenzi ${ }^{1}$, Dimitris Diamantidis ${ }^{2}$, Miroslav Sykora ${ }^{3}$ \\ DOI: https://doi.org/10.5592/CO/BSHM2017.4.7 \\ ${ }^{1}$ Civil Engineer, Lucca, Italy,, \\ ${ }^{2}$ Ostbayerische Technische Hochschule Regensburg, Pruefeninger Str. 58, Regensburg, 93025, Germany, \\ ${ }^{3}$ Klokner Institute, Czech Technical University in Prague, Šolínova 7, Praha, 16608 Praha 6, Czech \\ Republic, \\ E-mails: ${ }^{1}$ danielelenzi1989@gmail.com ; ${ }^{2}$ dimitris.diamantidis@oth-regensburg.de; \\ ${ }^{3}$ miroslav.sykora@cvut.cz
}

\begin{abstract}
Monitoring of structures and related decisions based on cost optimization are discussed in this contribution. Many research publications and experimental data are currently available on inspection and on monitoring and they represent the outcome of the remarkable work done. Not all the topics of interest are widely debated and implemented in standards. The current state-of-practice in standards is summarized and aspects to be included in future recommendations are proposed.

The implementation of risk-based decisions is illustrated in a case study dealing with a stadium roof in Northern Italy. Snow actions are important especially in northern and mountainous regions where heavy snowfalls and related accumulation result to considerable loads. As the roof structure fails to comply with the requirements of Eurocodes, a permanent monitoring system has been installed to allow for real time evaluation of the reliability level of the structure. The system supplies the necessary information supporting immediate decisions on closure of the stadium in case of an extraordinary snow load. Cost-optimal decisions regarding the closure of the stadium are analysed based on a limit state function, on probabilistic models for the influencing parameters including measurement uncertainty, economic losses related to closure and failure consequences. The results demonstrate the potential of the use of the monitoring systems and probabilistic reliability analysis in order to support decisions and highlight the need for their implementation in future standards.
\end{abstract}

Keywords: SHM, monitoring, probabilistic methods, reliability analysis, risk analysis, snow load, reliability level.

\section{Scope of the fact sheet}

The application of risk-based methods to illustrate the potential use of monitored results together with probabilistic reliability analysis is presented. The implementation into standards is outlined.

\section{Basis / standards}

The development of guidelines in the SHM sector was summarized in a previous fact sheet (Diamantidis et. al., 2015). Thereby the monitoring of the structural behaviour and the associated updating of the real performance and of the reliability of the structure were discussed. Risk and reliability analysis procedures are available and their implementation is shown in (Holicky et. al., 2014). An essential step for the assessment is the specification of target reliability levels (JCSS, 2001; Steenbergen et. al., 2015). The target reliability reflects the acceptable risk since it is associated with consequence classes (ISO 2394; EN 1990).

Guidelines, research publications and experimental data are currently available on inspection and on monitoring and they represent the outcome of the remarkable work done. A significant step thereby is to combine SHM with reliability and risk analysis methods in order to fulfil target safety levels also with support of monitored values. At such a stage alarm threshold for selected damage sensitive feature parameters can be set. More complex damage identification algorithms, including model based and non-model based approaches, can be selected and applied together with reliability analysis techniques. 
The implementation of risk-based decisions is illustrated in this fact sheet in a case study dealing with a stadium roof in Northern Italy. Snow loads are important especially in northern and mountainous regions where heavy snowfalls and related accumulation result to considerable loads. The method can be applied to other cases and appropriate decision support systems can be developed.

In recent years, multiple major snowstorms resulted in numerous roof failures. The current reference regarding snow loads in Europe is EN 1991-1-3 that accounts for roof slope, thermal characteristics of the structure, and exposure to wind to quantify the amount of snow that may be present on a roof over the course of a winter season.

\section{Application study}

The numerical example is focused on a stadium erected at the beginning of the 1990s and located in Trento, Northern Italy, at an altitude of $190 \mathrm{~m}$. The roof of the stadium consists of a cantilever steel beam IPE 500 (Fig. 1). The lengths of the first span and of the cantilever are $4 \mathrm{~m}$ and $8 \mathrm{~m}$, respectively. The spacing between adjacent beams is $5 \mathrm{~m}$. The inclination of the steel beam is negligible $\left(\alpha \approx 0^{\circ}\right)$.

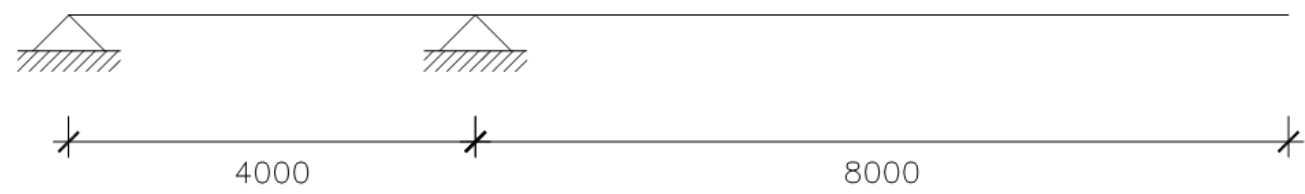

Fig. 1. Scheme of the roof beam

The stadium can accommodate up to 4000 people and it is widely used in order to host sport events, concerts and shows. As the structure is located in the Alpine region and it is subjected to high snow loads, after the recent roof collapses and the related studies, it has been decided to investigate its actual structural reliability. Analysis of past and present prescriptive codes reveals that the design snow load increased significantly over the last decades.

The former Italian standard D.M. 12.02.1982 recommended the following snow loads for zone I (Northern Italy):

$$
\begin{array}{ll}
q_{s}=0.9 \mathrm{kN} / \mathrm{m}^{2} & h_{s}<300 \mathrm{~m} \\
q_{s}=0.9+1.5\left(h_{s}-300\right) \mathrm{kN} / \mathrm{m}^{2} & h_{s} \geq 300 \mathrm{~m} \\
\alpha \leq 20^{\circ}: \text { no reductions } &
\end{array}
$$

$20^{\circ}<\alpha<60^{\circ}: 2.5 \%$ reduction (linear) for each degree of inclination of the roof

Considering the aforementioned characteristics, a snow load of $0.9 \mathrm{kN} / \mathrm{m}^{2}$ was assumed. The current code, D.M. 14.01.2008 (NTC 08), for the same site, leads to:

$$
q_{s}=\mu_{i} \cdot q_{s k} \cdot C_{e} \cdot C_{t}=0.8 \cdot 1.5 \cdot 1 \cdot 1=1.2 \mathrm{kN} / \mathrm{m}^{2}
$$

with $C_{e}=1$ (exposure coefficient), $C_{t}=1$ (thermal coefficient), $\mu_{i}=0.8$ (shape factor for a monopitch roof), $q_{s k}=1.5 \mathrm{kN} / \mathrm{m}^{2}$ (characteristic ground snow load for the Alpine region and for altitude over $200 \mathrm{~m}$ ). The calculated values indicate that snow loads currently assumed are higher than in the past and for this reason many existing structures subjected mainly to snow loads do not achieve the same reliability level imposed to the new structures in modern codes. In order to keep the reliability level of the stadium classified in the highest consequence class CC3 (EN1990, 2002) acceptable, it was decided to implement on the roof of the stadium a permanent online monitoring system of the snow depth (Lanzinger and Theel, 2010). The purpose of the implementation of this permanent monitoring system is to close the stadium and forbid the presence of people in it when the snow depth reaches a threshold value $d_{\mathrm{lim}}$ and reliability of the roof cantilevers drops below a specified target level. 


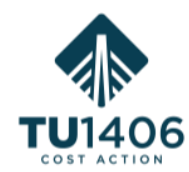

The probabilistic reliability analysis is based on the limit state function $Z(\mathbf{X})$ for the section of the beam subjected to the maximum bending moment:

$$
\mathrm{Z}(\boldsymbol{X})=\vartheta_{R} W_{\mathrm{pl}} f_{\mathrm{y}}-\vartheta_{E} L^{2} / 2\left[\gamma_{\text {steel }} \cdot A_{\mathrm{s}}+g_{\text {roof }} b+\mu_{i} \times \gamma_{\text {snow }}(d) \times b \times d\right]
$$

Notation and probabilistic models of all the basic variables based on the recommendations of (JCSS, 2001) are provided in Table 1.

Table 1. Models of basic variables

\begin{tabular}{|c|c|c|c|c|}
\hline $\begin{array}{l}\text { Basic } \\
\text { variable }\end{array}$ & Dist. & Mean & $\mathrm{CoV}$ & Note \\
\hline $\begin{array}{l}\text { Resist. model } \\
\text { unc., } \vartheta_{R}\end{array}$ & $\mathrm{LN}$ & 1.1 & 0.05 & $\begin{array}{l}\text { Yielding resistance for bending without loss of stability (Nadolski and } \\
\text { Sykora, 2015) }\end{array}$ \\
\hline $\begin{array}{l}\text { Section } \\
\text { modulus } \\
\text { IPE500, } W_{\mathrm{pl}}\end{array}$ & DET & $0.002194 \mathrm{~m}^{3}$ & - & - \\
\hline $\begin{array}{l}\text { Yield } \\
\text { strength } \\
\mathrm{S} 275, f_{\mathrm{y}}\end{array}$ & $\mathrm{LN}$ & $308.6 \mathrm{MPa}$ & 0.07 & - \\
\hline $\begin{array}{l}\text { Load eff. } \\
\text { unc., } \vartheta_{E}\end{array}$ & $\mathrm{LN}$ & 1 & 0.05 & $\begin{array}{l}\text { Reduced variability considered for the structural system with small } \\
\text { uncertainties in idealisation of supports and in composite actions of the } \\
\text { cantilevers. }\end{array}$ \\
\hline $\begin{array}{l}\text { Span of } \\
\text { cantilever, } L\end{array}$ & DET & $8 \mathrm{~m}$ & - & - \\
\hline $\begin{array}{l}\text { Steel density, } \\
\gamma_{\text {steel }}\end{array}$ & $\mathrm{N}$ & $77 \mathrm{kN} / \mathrm{m}^{3}$ & 0.01 & - \\
\hline $\begin{array}{l}\text { Sectional area } \\
\text { IPE } 500, A_{\mathrm{s}}\end{array}$ & DET & $0.01155 \mathrm{~m}^{2}$ & - & - \\
\hline $\begin{array}{l}\text { Weight of } \\
\text { roofing, } g_{\text {roof }}\end{array}$ & $\mathrm{N}$ & $0.5 \mathrm{kN} / \mathrm{m}^{2}$ & 0.05 & $\begin{array}{l}\text { Variability could be reduced by measurements; additional cost however } \\
\text { cannot be justified due to low sensitivity factor of this variable. }\end{array}$ \\
\hline $\begin{array}{l}\text { Spacing of } \\
\text { cantilevers, } b\end{array}$ & DET & $5 \mathrm{~m}$ & - & - \\
\hline $\begin{array}{l}\text { Shape factor, } \\
\mu_{i}\end{array}$ & $\mathrm{~N}$ & 1 & $\begin{array}{l}0.05 \\
(0.15)\end{array}$ & $\begin{array}{l}\text { The coefficient covers deviation of the snow load on the roof from a } \\
\text { uniform distribution. The reduced value of CoV is based on the } \\
\text { judgement of the authors for this case study while the larger estimate is a } \\
\text { general recommendation in (JCSS, 2001). Note that the coefficient does } \\
\text { not make distinction between the snow loads on the ground and on the } \\
\text { roof in case of snow depth monitoring. }\end{array}$ \\
\hline $\begin{array}{l}\text { Snow density, } \\
\gamma_{\text {snow }}(d+\Delta d)\end{array}$ & $\mathrm{LN}$ & $\begin{array}{l}1.09 d+2.4 \\
\text { in } \mathrm{kN} / \mathrm{m}^{3} \text { for } \\
d \text { in } \mathrm{m}\end{array}$ & 0.2 & $\begin{array}{l}\text { The mean is an average of estimates obtained by the snow density } \\
\text { models provided in (ISO } 4355,2013 \text { ) for the location of the stadium. } \\
\text { CoV is obtained by comparing outcomes of the ISO } 4355 \text { models; CoV } \\
\text { can be considered independent of snow depth for } d<1 \mathrm{~m} \text {. }\end{array}$ \\
\hline $\begin{array}{l}\text { Snow depth, } \\
d\end{array}$ & $\mathrm{~N}$ & $\begin{array}{l}\text { Monitored, in } \\
\mathrm{m}\end{array}$ & $\begin{array}{l}\text { See } \\
\text { note }\end{array}$ & $\begin{array}{l}\text { Standard deviation of } 0.01 \mathrm{~m} \text { is considered to account for measurement } \\
\text { uncertainty; the most unfavourable value from measurements from } \\
\text { several locations on the roof is considered. }\end{array}$ \\
\hline
\end{tabular}

Considering limit state function (3), the variation of reliability index $\beta$ (EN 1990, 2002) with snow depth $d$ is displayed in Fig. 2 for the two alternative values of the coefficient of variation of $\mu_{i}$ (Table 1). It is observed that the increased value of $\mathrm{CoV}$ of the shape factor leads to significant drop of the reliability level, about 0.5 in terms of $\beta$ and the probabilistic model of $\mu_{i}$ deserves a careful consideration in a more advanced analysis. 


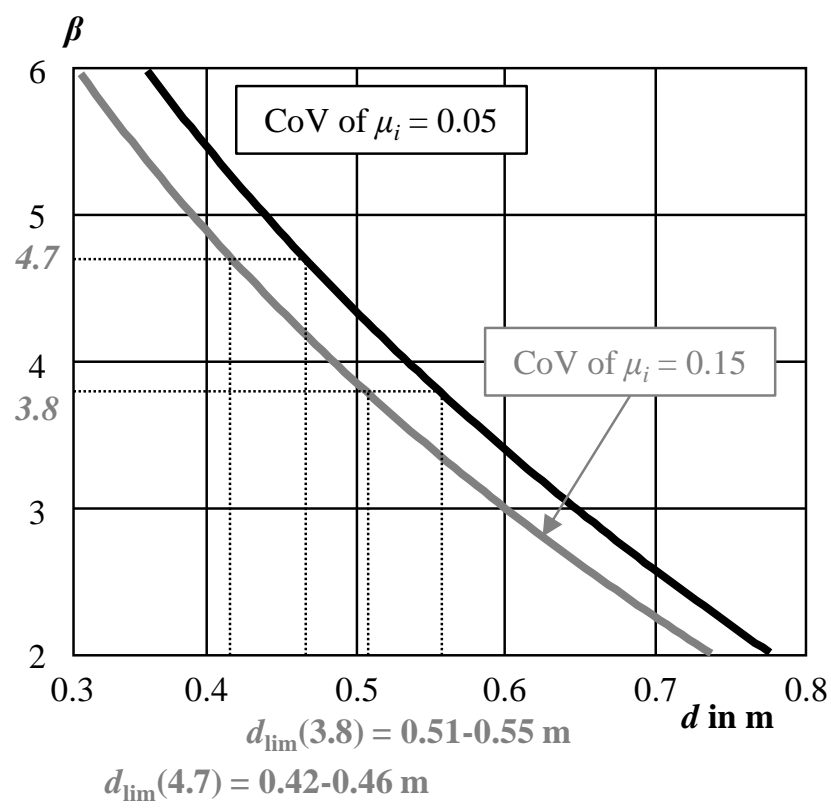

Fig. 2. Variation of reliability index $\beta$ with snow depth $d$ and limiting values $d_{\lim }$ for the selected target levels.

Considering CoV of $\mu_{i}=0.05$, the FORM analysis indicates the dominating role of uncertainties in snow density (sensitivity factor -0.84), moderate influence of steel yield strength and model uncertainties (absolute values of sensitivity factors between 0.2-0.35) and minor influence of the other random variables included in limit state function (3). The detailed investigation of uncertainties in snow density is beyond the scope of this fact sheet. However, it is noted that the probabilistic model given in Table 1 is in a good agreement with more elaborated models proposed by (Pistocchi, 2016) for Alpine and Maritime areas, by (Jonas et al., 2009) for Swiss Alps and by (Sturm et al., 2010) for regions in the United States, Canada, and Switzerland.

When a target reliability level is specified, a limit value $d_{\text {lim, above which reliability becomes }}$ unacceptable and the stadium must be temporarily closed, can be obtained from Fig. 2. However, target levels for such temporary situations are typically not provided in standards. Recently (Tanner and Hingorani, 2016) proposed a procedure to derive target levels for short-term situations; however a widely accepted approaching is missing and is far to be standardised.

Therefore, a simplified cost-benefit analysis is conducted to decide about the use of the stadium on the basis of the balance between the benefits and the expected failure consequences. The use of the stadium is authorised when the associated benefit $B$ exceeds the probability of failure dependent on snow depth $p_{\mathrm{F}}(d)$, multiplied by the consequences of failure $C_{f}$ :

$$
B \cdot\left[1-p_{\mathrm{F}}(d)\right] \approx B \geq C_{\mathrm{f}} \cdot p_{\mathrm{F}}(d)
$$

$B$ and $C_{f}$ need to be expressed in the same units. Failure costs $C_{\mathrm{f}}$ include cost of repair or replacement of the structure, economic losses due to non-availability or malfunction of the structure, societal consequences (costs of injuries and fatalities that can be expressed e.g. in terms of compensations or insurance cost), unfavourable environmental effects and other (loss of reputation, introducing undesirable 'non-optimal' changes of design practice). Usually monetary units can be used to combine the various contributors to failure costs.

Realistically assuming that the benefit is less than the failure costs, $B<C_{\mathrm{f}}$, then the target failure probability based on the economic optimisation, $p_{T}$, is obtained from Equation (4):

$$
p_{F}(d) \leq p_{T} \approx B / C_{f}
$$

The reliability index corresponding to the target probability is (for $B<C_{f}$ ):

$$
\beta_{T}=-\Phi^{-1}\left(p_{F, e c o}\right) \approx-\Phi^{-1}\left(B / C_{f}\right)
$$



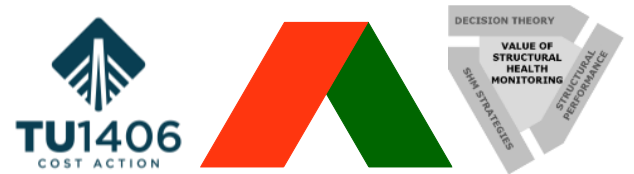

where $\Phi^{-1}$ is the inverse cumulative distribution function of the standardised normal distribution. The target reliability index $\beta_{T}$ is related to a short period of a single snowfall, say in terms of one to a few weeks, for which the stadium is to be temporarily closed. Fig. 3 indicates the variation of the target reliability index $\beta_{T}$ with the ratio $B / C_{f}$ reflecting though the sensitivity of the obtained results. The target level is approximately linearly proportional to the order of magnitude of the ratio, which is commonly less than 0.001 .

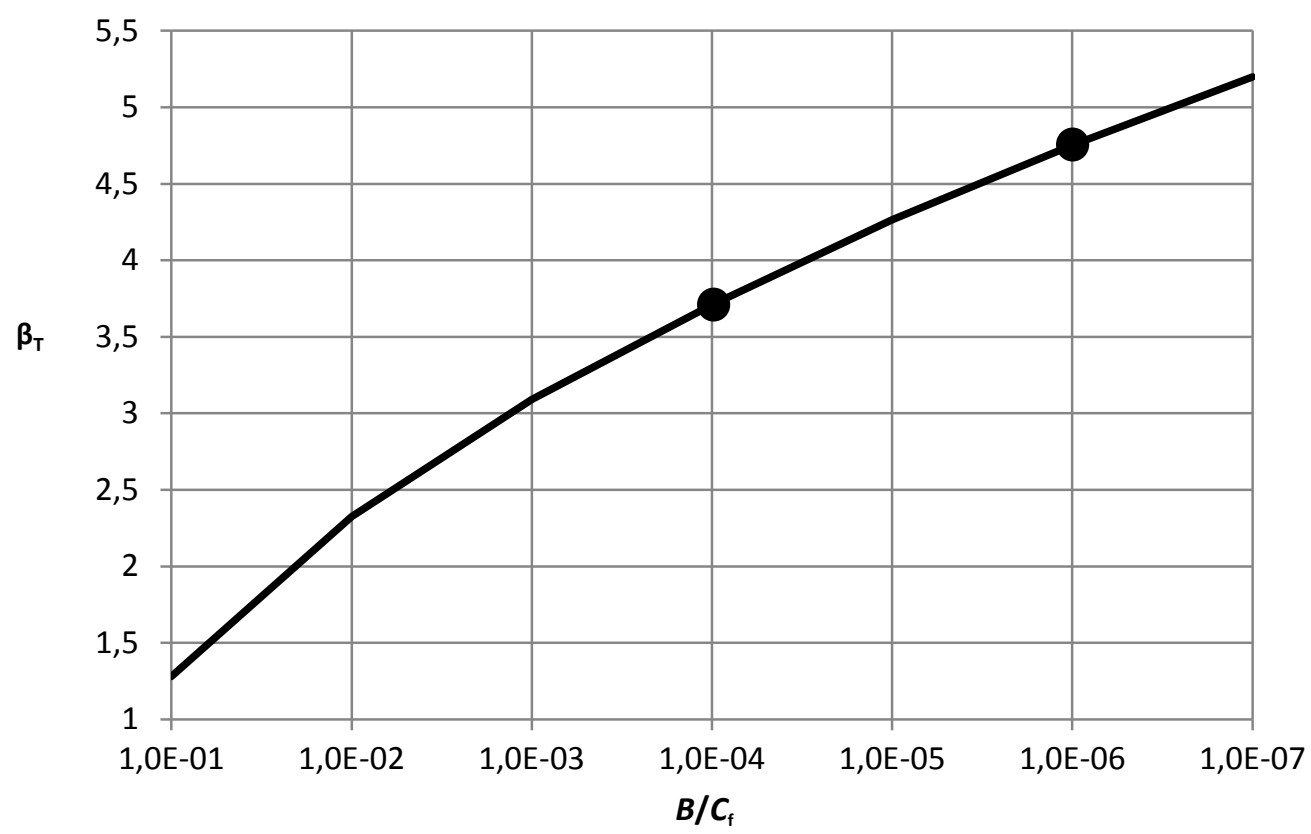

Fig. 3. Variation of the target reliability index $\beta_{T}$ with the ratio $B / C f$

A possible approach is to consider the benefit as the average income deriving from the tickets sold to the public for a certain event and calculated multiplying the ticket cost and the number of tickets sold. Possible values for the ticket cost range from $1 €$ to $100 €$. Human failure consequences dominate the total consequences and can be transformed into monetary units by multiplying the expected number of fatalities and the Societal Value of a Statistical Life (SVSL) according to the Life Quality Index approach (ISO 2394, 2015). The order of magnitude of the SVSL is taken here as $1000000 €$. It follows that plausible values for the ratio $B / C_{f}$ are comprised between approximately $10^{-4}$ and $10^{-6}$. The corresponding $\beta_{T}$ values are thus ranging between approximately 3.7 and 4.8 (Fig. 3). Based on these estimates, Fig. 2 portrays the limit values of snow depth.

It is noted that the presented cost-benefit analysis assumes that the stadium is operated by a public authority. In the case of a private owner, the SVSL should be replaced by compensation costs related to harm to the users that would need to be specified considering insurance of the company. Further, societal (group) risk criteria for human safety (ISO 2394, 2015; Steenbergen et. al., 2015; Sykora et al., 2016) should be applied in order to verify whether the audience is exposed to excessive safety risks.

It is emphasised that the presented analysis is simplified to illustrate the key steps of decision making and interpreting monitoring results. Future extended studies will investigate also the system aspects of reliability analysis and failure consequence modelling. A simplified approach applied by (Sýkora et al., 2014) for a roof structural system exposed to extreme wind loading is to be utilised.

\section{Conclusions}

The reliability analysis of the study case reveals that the roof of the stadium is able to sustain snow loads comparable with the snow load currently imposed by the Italian code for new structures. 
This system provides a real time evaluation of the reliability level and supports decisions regarding closure of the stadium in case of heavy snowfalls or excessive snow accumulation. This does not prevent possible damages to the structure but avoids fatalities and injuries, thus considerably reduces the total consequences of failure. The analysis can include in more detail the discussed uncertainty contributors.

The simplified case study shows the potential of structural monitoring and provides the methodology on how monitoring and probabilistic reliability analysis can improve decisions about utilisation of structures. The methodology can be extended to a posterior decision analysis implementing the conditional value of sample information (Straub, 2004). Also the consideration of past satisfactory performance can be included in the analyses (Holicky et.al., 2014, Diamantidis et. al., 2015).

Applications of the described procedure can bring considerable societal benefits related to performance of important structures and infrastructures such as stadiums, bridges, congress halls, multi-purpose arenas or structures in energetics. The methods can be applied following the principles of new Eurocodes under development, especially those related to the evaluation of existing structures, to fulfil the imposed target levels of reliability. They allow namely the direct evaluation of reliability and risk and lead to interventions for keeping them below specified acceptable levels.

\section{Acknowledgements}

This study was supported by the Regensburg Center of Energy and Resources (RCER) of the Ostbayerische Technische Hochschule Regensburg (OTH Regensburg) and by the Ministry of Education, Youth and Sports of the Czech Republic under Grant LD15037. COST Action TU1402 on Quantifying the Value of Structural Health Monitoring is gratefully acknowledged for networking support.

\section{References}

Dimitris Diamantidis, Miroslav Sykora, Milan Holicky. Updating information on the real performance of structures - experience gained and implementation in future guidelines. 1st Workshop COST TU1402 on Quantifying the Value of SHM, Lyngby, Denmark, 2015.

D.M. 12.02.82. Criteri generali per la verifica di sicurezza delle costruzioni, dei carichi e dei sovraccarichi (in Italian), Italy, 1982.

D.M. 14.01.2008. Nuove Norme Tecniche per le Costruzioni (in Italian), Italy, 2008.

EN 1990. Eurocode - Basis of structural design. CEN European Committee for Standardization, Brussels, Belgium, 2002.

EN 1991-1-3. Eurocode - Actions on structures - Part 1-3: General actions - Snow loads. CEN European Committee for Standardization, Brussels, Belgium, 2004.

Milan Holický, Dimitris Diamantidis et al. Methods for the risk assessment and risk-based management of aging infrastructures. Lifelong Learning Programme, Prague, Czech Republic, 2014.

ISO 2394. General principles on reliability for structures. ISO, Geneva, Switzerland, 2015.

ISO 4355. Bases for design of structures - Determination of snow loads on roofs. ISO, Geneva, Switzerland, 2013.

JCSS (Joint Committee on Structural Safety). Probabilistic model code. Available online at www.jcss.byg.dtu.dk

Tobias Jonas, Christoph Marty and Jan Magnusson. Estimating the snow water equivalent from snow depth measurements in the Swiss Alps. Journal of Hydrology 378: 161-167, 2009, DOI: http://dx.doi.org/10.1016/j.jhydrol.2009.09.021

Eckhard Lanzinger and Manfred Theel. Improving reliability and sensitivity of a laser snow depth gauge. Presentation at TECO 2010, Helsinki, Finland, 2010.

Alberto Pistocchi. Simple estimation of snow density in an Alpine region. Journal of Hydrology: Regional Studies 6: 82-89, 2016, DOI: http://dx.doi.org/10.1016/j.ejrh.2016.03.004

Raphaël D.J.M. Steenbergen, Miroslav Sykora, Dimitris Diamantidis, Milan Holicky, A.C.W.M. Vrouwenvelder. Target reliability levels for assessment of existing structures based on economic optimisation and human safety criteria. Structural Concrete Journal, Vol. 16, 2015. 

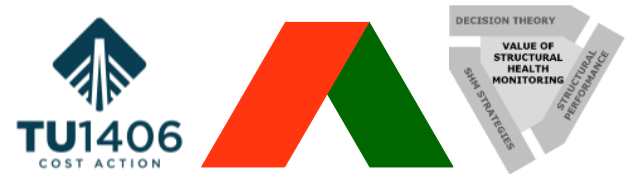

The Value of Structural Health Monitoring for the reliable Bridge Management

Daniel Straub. Generic approaches to risk Based inspection planning for steel structures. IKB Bericht 284, vdf Hochschulverlag ETH Zürich, Switzerland, 2004.

Matthew Sturm, Brian Taras, Glen E. Liston, Chris Derksen, Tobias Jonas and Jon Lea. Estimating Snow Water Equivalent Using Snow Depth Data and Climate Classes. Journal of Hydrometeorology 11(6): 1380-1394, 2010, DOI: 10.1175/2010JHM1202.1

Miroslav Sykora, Milan Holicky, Karel Jung, Dimitris Diamantidis. Target reliability for existing structures considering economic and societal aspects. Structure and Infrastructure Engineering 13(1): 181-194, 2017, ISSN 1573-2479 (Print), 1744-8980 (Online), DOI: 10.1080/15732479.2016.1198394

Miroslav Sýkora, Milan Holický and Dimitris Diamantidis. Probabilistic updating in the reliability assessment of industrial heritage structures. Heron 59(2/3): 59-78, 2014, ISSN 0046-7316.

Vitalij Nadolski, Miroslav Sykora. Model Uncertainties in Resistances of Steel Members. Proc. ESREL 2015, Zurich, 7-10 September 2015, Leiden, Balkema/CRC Press, 2015.

Peter Tanner, Ramon Hingorani. Acceptable risks to persons associated with building structures. Structural Concrete, Vol. 16, 2015.

Peter Tanner, Ramon Hingorani. Risk assessment under temporary use conditions. Proc. Challenges in Design and Construction of an Innovative and Sustainable Built Environment, 19th IABSE Congress Stockholm, 21-23 September 2016, 2016. p. 899-907. 